\title{
EXAMINING THE REPRESENTATION OF SOCIAL ACTORS IN FASD PREVENTION CAMPAIGNS
}

by

Riki Yandt, BSW, University of Regina, 2014

\author{
An MRP \\ presented to Ryerson University \\ in partial fulfillment of the \\ requirements for the degree of \\ Master of Social Work \\ in the program of \\ Social Work
}

Toronto, Ontario, Canada, 2020

(C) Riki Yandt, 2020 


\begin{abstract}
AUTHOR'S DECLARATION
I hereby declare that I am the sole author of this MRP. This is a true copy of the MRP, including any required final revisions.
\end{abstract}

I authorize Ryerson University to lend this MRP to other institutions or individuals for the purpose of scholarly research

I further authorize Ryerson University to reproduce this MRP by photocopying or by other means, in total or in part, at the request of other institutions or individuals for the purpose of scholarly research.

I understand that my MRP may be made electronically available to the public. 


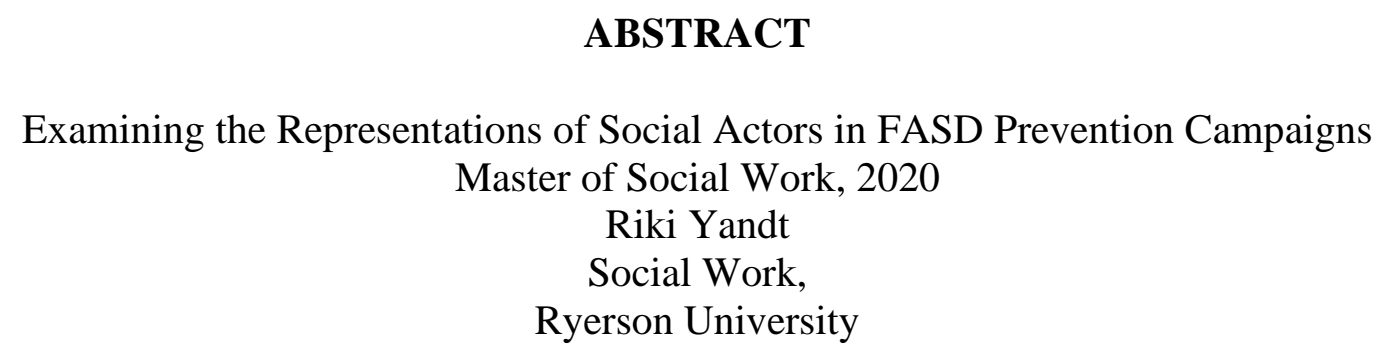

Through an exploration of public health campaigns targeting the prevention of FASD, I identified and challenged the concepts of mother blame and stigma found within the discursive practices of the medical system. Framed by feminist theory and critical discourse analysis (CDA), I used van Leeuwan's approach to social actors to name and explore the representations of people depicted within the campaigns. The discussion focuses on how the current discourse on FASD informs the way that people are perceived and explores possible avenues to challenge and shift the way that substance use is discussed in relation to women and pregnancy. 


\section{ACKNOWLEDGEMENTS}

I would like to express my gratitude to the many people who supported me in developing and completing my masters research paper. This was no easy feat for me, as I am sure that is the experience of many. Specifically, I would like to thank Lauryn, April, Erin and Mariko for your continued encouragement and warmth during this journey.

In addition to this, I would like to extend a big thank you to my research project supervisor Susan Preston and the School of Social Work at Ryerson University for their patience and support in seeing this project through. 


\section{TABLE OF CONTENTS}

Chapter 1: Introduction

Page 1

Chapter 2: Literature Review

Page 3

Chapter 3: Theoretical Framework

Page 15

Chapter 4: Methodology

Page 19

Chapter 5: Analysis

Page 26

Chapter 6: Discussion

Page 36

Chapter 7: Conclusion

Page 43

Reference List

Page 48 


\section{LIST OF APPENDICES}

Appendix A - Campaign \#1

Appendix B - Campaign \#2

Appendix C - Campaign \#3
Page 44

Page 46

Page 47 


\section{Chapter 1: INTRODUCTION}

"I just couldn’t believe it," Mercredi said. "Life is so precious, right? How could they just throw it away like nothing? She probably didn't even have a name." (Deibert, Short, \& Vescera, November, 2019, para 13)

This quote was taken out of the Saskatoon StarPhoenix on November 12 of 2019, where a post mortem infant is discovered in a recycling bin by the civilian quoted above. The story, although not unique, is one that stirs the conscience of many people. What follows is a lively debate in the city about the benefits of an anonymous drop spot for people to safely and humanely leave their infants, and a plea released by the police for the person (presumably mother) to turn themselves in. In 2017 this same scenario occurred in the city of Calgary, where a then 19 year-old woman was found, arrested and charged for leaving behind her day-old infant (Pearson, 2020). The dichotomy that is created in these scenarios is one where the infant is the victim, and the mother is the perpetrator; the mother holding the burden of blame. Such classifications reinforce binary thinking and do not acknowledge the fluidity between the categories of good versus evil, and how someone can occupy both and neither category simultaneously.

The reason that I bring these stories to the forefront of my project is because it highlights the lack of agency women have and the normalization of popular discourse that supports this dichotomy. Although the scenarios that led to the dichotomy above may seem to be an extreme, it is replicated in other areas as well, for example: children and second-hand smoke; children and nutrition, especially around childhood obesity; children on medication for mental health challenges; children (inclusive to adult children) who commit crimes; and children with fetal alcohol spectrum disorder (FASD). The burden of blame on the mother is insidious for it begins 
at the moment of conception and grows throughout a child's life, whereby the blame encompasses any child maladjustments and extends to the predicaments a woman might find herself in, including poverty and substance use (Jackson \& Mannix, 2004). Mothers are blamed not only for their own life circumstances, but also for those of their child regardless of external factors and influences. This paper focuses on the issue of mother blame found in discourse about FASD. Using a feminist approach to CDA, this research examines the healthcare system as manifested through public health promotional campaigns targeting the prevention of FASD, it is going to ask the question of who is being identified in the campaigns, and examine how they are being represented. This paper begins with a predominantly medicalized literature review on FASD; the purpose of this review is to give the reader a basic understanding of substance use during pregnancy and the ways that it is discussed in a health care setting. From there I guide the reader through the theoretical framework, methodology and design of the study, analysis and a discussion surrounding the implications of the findings. 


\section{CHAPTER 2. LITERATURE REVIEW}

Fetal Alcohol Spectrum Disorder (FASD) is a complex disability that touches multiple sectors, including child and youth welfare, social work, health care, justice, education and more. As a relatively new field of research, FASD has substantial gaps in the professional knowledge that currently exists. My literature review examines articles on the medical evolution of FASD, FASD and stigma, and FASD as it relates to the Truth and Reconciliation Commission (TRC).

FASD was originally coined as a medical diagnosis by health care professionals, but today we have seen it evolve as more than just a health issue. As a social worker with an interest in applying a public health perspective to this literature review, I am taking a close look at how the medical field has dominated the discourse on FASD since 1973 and the gendered history that is enmeshed within it. The western medical field is firmly rooted in male dominance; this can be seen through the materials taught which are mainly authored by cis-men at institutions where cismen take up the majority of leadership roles, and has a history of objectification which transfers

to both patients and colleagues (Sharma, 2019). The gendered history of medicine is important in this research because when the subject of inquiry is FASD, the focus is most often a woman's relationship to alcohol and its impact on her child (Chaote \& Badry, 2019). FASD, as an example of male dominance, may elicit strong opinions and reactions from people with respect to alcohol consumption while someone is pregnant. I challenge the reader to sit with this discomfort while we unpack some contested areas and nuances of FASD in Canada.

\section{FASD: A Medical Overview}

In 1973, an article was published in the medical journal The Lancet that first featured the term Fetal Alcohol Syndrome (FAS) which was coined by pediatricians Drs. Kenneth Lyons Jones and David W. Smith from the University of Washington School of Medicine (Jones \& 
Smith, 1973). Drs. Jones and Smith studied 11 cases of children in the U.S. born to chronic alcoholic mothers. The results led them to develop the first diagnostic tool for FAS, which examined features such as growth deficiency, the presence of an intellectual disability, and characteristic changes in the facial structure (Jones \& Smith, 1973; Jones \& Streissguth, 2010).

Canada released its diagnostic guidelines for FAS in 2005 which reflected the 1973 U.S. model. The Canadian diagnostic guidelines added a key recommendation that individuals should be assessed by a multidisciplinary team of specialists, including a nurse or social worker, physician, psychologist, occupational therapist and speech pathologist (Chudley et al., 2005). Notable challenges to the 2005 diagnostic guideline acknowledged by the authors include the reluctance of mothers to share with their doctors that they had consumed alcohol, the lack of services in rural communities, and the need for health care practitioners to complete FAS diagnostic training (Chudley et al., 2005).

FASD evolved as a diagnosis in 2016 and is believed to be a leading cause of neurodevelopmental delays in Canadians (Cook et al., 2016). In Canada it is estimated that over 3,000 babies a year are born with FASD, and about 300,000 people are living with the disability (Cook et al., 2016). The diagnostic guidelines released in 2016 recognizes FASD as a full body spectrum disorder that impacts individuals to varying degrees and FASD is now recognized as a lifelong disability that requires continued support (Cook et al., 2016). Neurological based disabilities linked to FASD include motor skills; neuroanatomy/neurophysiology; cognition; language; academic achievement; memory; attention; executive function, including impulse control and hyperactivity; affect regulation; and adaptive behaviour, social skills or social communication (Cook et al., 2016). Without confirmation of alcohol consumption by the mother or by a trained medical professional, a person who experiences symptoms related to FASD will 
not receive a full diagnosis, instead they will be given a diagnosis of Partial Alcohol Exposure (PAE) and are seen to be "at risk" of having FASD (Cook et al., 2016).

McLennan and Braunberger (2017) released a critique of the Canadian diagnostic guidelines on FASD challenging the diagnostic method for PAE as the criteria related to the diagnosis is similar to many mental health disorders (ADHD, bipolar, personality disorders) whose etiology is not found in the exposure to alcohol. McLennan and Braunberger (2017) are concerned that the adoption of PAE as a diagnostic term will result in the misdiagnosis of people living with a mental illness to carry the label of PAE, a diagnosis rife with stigma, as discussed below.

\section{Stigma associated with FASD}

"A stigma is an attribute that makes a person different from others in a social category, it reduces the person to a tainted or discounted status" (Goffman, 2006, p. 133). Using Goffman's (2006) definition of stigma, McLennan and Braunberger (2017) are concerned with PAE 'tainting' a person with a mental illness, however, people living with mental illness are already in a social category that 'discounts' their status thus would have the effect of stratified discounting.

Dr. Klein (2016) of Ontario, echoed the sentiments of McLennan and Braunberger (2017) by expressing that the harm of misdiagnosing children with FASD is in the attachment of a label that has its etiology in prenatal alcohol exposure. Dr. Klein (2016) elaborates on these sentiments by stating "basing resources on an etiologic label marginalizes individuals with neurobehavioral disabilities without a unifying diagnostic label" (p. 1035). In the article Dr. Klein (2016) makes his position clear that an FASD diagnosis is harmful and unnecessary when resources should go towards diagnosing "functional impairment rather than often futile (and sometimes damaging) 
attempts to attribute causality" (p. 1036). What Dr. Klein is alluding to is that people who experience neurological disabilities need one unifying diagnosis not many, and especially not ones that identify alcohol. This is an example of a medical professional carrying stigmatized views towards FASD, for the naming of alcohol consumption as an undesirable attribute carries shame. Stigma is not solely attributed to the diagnosis of FASD, but also to the consumption of alcohol by the parent.

Canada's former Deputy Chief Public Health Officer David Mowat describes public health's role as "prepar[ing] for and respond[ing] to emergencies and also [to] improve the health status of the population, reduce disparities and enhance the sustainability of the health services system" (Mowat \& Butler-Jones, 2007, p. 32). A public health perspective on FASD widely focuses on the relationship between the mother's use of alcohol and its impact on the child: interestingly within literature focused on the subject, the discourse of blame in maternal alcohol use is often followed by the acknowledgement of stigma in the field without recourse on how to shift it (Chaote \& Badry, 2019).

A public service announcement addressed to women by the U.S. Surgeon General in 2005 stated that "no amount of alcohol consumption can be considered safe during pregnancy" and that "alcohol-related birth defects are completely preventable" (Surgeon General, 2005, p. 1). This is a widely-published sentiment by governing health authorities, such as the Public Health Agency of Canada (PHAC) where the discourse surrounding FASD claims that there is no safe amount of alcohol consumption during pregnancy and that FASD is a disability that is 100\% preventable (Chudley et al., 2005; Health Canada, 2006; PHAC, 2007). This information is inaccurate, harmful and misleading. By directing the information solely to women, it makes the assumption that pregnancies are isolated events when in reality they are complex and involve 
many ecological relations such as a person's support system, systemic supports, economic situation, and substance use (Chaote \& Badry, 2019). Stating that there is "no safe amount" dismisses that abstinence may be unrealistic for some, and because there's no clear guidelines on safe amounts, the sweeping abstinence based message removes the ability for the target of that messaging to make an informed decision with all the information present (Zizzo \& Racine, 2017). The second statement that claims FASD is $100 \%$ preventable is misleading in that it places the onus of an alcohol-free pregnancy solely on the maternal carrier, for FASD is only prevented if the pregnant person does not consume alcohol. However, alcohol continues to be a widely accepted and available substance and as long as people continue to have unprotected sex (or protected, for many birth control methods are not 100\% effective), prenatal alcohol exposure will continue to exist and be a risk.

A person who is viewed as bad, dangerous or weak is reduced in our minds from a whole person to one that is tainted or discounted (Goffman, 2006). The type of public health messaging shown above supports abstinence-based models of care that carry shame and stigma in expressing that mothers are to blame for the child's FASD disability, implying that if she just stopped drinking then her child would not have FASD and thus would be seen as whole rather than the tainting of them both. Stigmas, like language, are socially constructed in ways what can be seen as a deeply discrediting attribute in one community, may be the norm in another (Goffman, 2006). An example of this can be found in the usualness of familial, partnered or peer alcohol consumption; in some families, addictions are normalized and the regular consumption of substances is integral for a sense of belonging and to not be seen as an outsider. In some situations the refusal of alcohol intake in an environment where consumption is the norm, can prove to be unfavourable as it has been found that rates of domestic violence increase with the 
news of a pregnancy (Finnbogadottir \& Dykes, 2016). This means that a person may choose to drink in order to conceal that they are pregnant and/or the alternative of saying no, may result in worst harms than consumption.

If the role of public health in Canada is to provide health promotion and protection to its people, who is it that they are protecting and promoting health for? One possible answer to this is found within the work of Deborah Lupton (2013) in regards to the growing infantilization of the unborn in the public domain (such as the renaming of an embryo and/or fetus as a baby) which she credits to the widespread use of ultrasound images. In her work Lupton explains that:

These developments have significant implications for the ways in which legislation is created and enforced in relation to pregnant women and their unborn and the relative rights and responsibilities that are accorded to women in relation to the unborn. The state of pregnancy has become a highly public experience, with women's 'baby bumps' scrutinised for their shape and size and their consumption and comportment of their bodies under surveillance from others and judged on whether they conform to expectations about appropriate pregnant behaviour. (p.3)

Based on this understanding, public health's current discourse on FASD has streamlined their focus on the protection of the unborn over the acknowledgment and concern for the wellbeing of the mother. If we view the unborn as a person with the understanding that a person has state sanctioned legal protection, then we are viewing women in their relationship to the unborn as potentially causing criminal harm to the unborn. This issue then comes full circle to the challenges of diagnosing a child with FASD without confirmation of alcohol exposure from the mother (Chudley et al., 2005); if a person is looked upon as if they are committing a crime or are viewed as 'tainted' for their deviance from being good, that presents a real barrier for women 
to be able to talk about alcohol consumption during pregnancy with medical professionals with whom this discourse originates with.

This stigmatizing view of women who use alcohol during pregnancy causes women to disengage with the messaging (Corrigan et al., 2018), as a result this can add barriers for many who may not feel comfortable disclosing their alcohol use during pregnancy (Salmon, 2011). Without confirmation, as discussed previously, there are consequences on whether or not someone with FASD is able to get a diagnosis (Chudley et al., 2005) thus affecting systemic support an individual may receive. Gonzales et al. (2018) highlight their concern with public health prevention messaging being focused on changing individual behaviour and they associate this concern with low public engagement, arguing that the messaging is not inclusive of the complex realities that women, and especially Indigenous women encounter (which will be discussed below). The argument here is that public health's shallow focus on the subject on FASD prevention is closing opportunities for engagement rather than it being a contributing point of entry for those conversations to happen.

On a professional level, having conversations about alcohol use during pregnancy with friends and clients is often difficult to navigate. When having these conversations, professionals will often draw upon their own personal experiences and social/relational perspectives to bridge the conversation with their clients (Bagley \& Badry, 2019). Professionals needing to bridge conversations using their own experience could be because there is no mandatory training or best practices in relation to FASD in the human service setting, and/or because a practitioner has their own experiences outside of the profession that shapes their responses to it (Bagley \& Badry, 2019). Relating non-clinical experiences in a clinical setting is not inherently a bad thing, however a medical professional's bias and attitudes towards who is seen to be "at risk" for 
having FASD can have serious implications for whom they deem fits the criteria for an FASD assessment (Bagley, 2019). In order to assess who is seen to be at-risk, Brownstein-Evans (2001) suggests that a person must have an understanding of who is seen to be not at risk. This notion conjures up the narrative of the good mother, an idealized view of a woman as a caregiver that embodies the virtues of being "self-sacrificing, nurturing, responsible, good, and moral" (p. 163). The subjective qualities of a good mother are then used to call into question anyone who may deviate from said virtues. This especially occurs for those who use substances, are lowincome, and/or are a single parent household which is then further scrutinized based on a persons racial, ethnic and cultural background (Brownstein-Evans, 2001). These virtues are grounded in colonial and patriarchal views, views that are supported and enacted by western Canada, inclusive of the medical field (Scott, 2019).

An example of these ideals is explored by Gonzales et al. (2018) who bring into discussion the over representation of Indigenous peoples with an FASD diagnosis, highlighting the stereotypes held of alcohol consumption in Indigenous communities, and the perception of Indigenous mothering being flagged as 'bad'. Another example of "at-risk" assumptions in the medical field is explored by Becerra et al. (2014) who note that white presenting children are more likely than non-white presenting children to be assessed and diagnosed for autism, when presented with the same neurodevelopmental symptoms as the latter group. This could imply that when presented with a child exhibiting neurodevelopmental symptoms, professionals may be more likely to request an FASD assessment for an Indigenous child and an autism assessment for a white child. The consequences of the examples previously provided is two-fold. First, we see a bias exhibited by professionals that perpetuates the colonial and patriarchal construction of who is seen to be "at-risk". This bias acts as a blinder in the sense that people may not be 
receiving adequate assessments, thus resulting in a wrongful diagnosis and being offered treatments and options that may not be best suited to the patient.

The stereotyping, racism and discrimination of Indigenous people by the healthcare system has justly caused a mistrust in that system. Indigenous women have undergone forced sterilization by medical professionals in Canada and have a real fear of discussing alcohol use for the result can and historically has been the removal of their children (Gonzales et al., 2018).

\section{FASD and the TRC}

In 2015, the TRC released its final report detailing the legacy of residential schools in Canada. 94 calls to action were identified within the report, two of which (\#33 and \#34) are directly related to the support and prevention of FASD:

33. We call upon the federal, provincial, and territorial governments to recognize as a high priority the need to address and prevent Fetal Alcohol Spectrum Disorder (FASD), and to develop, in collaboration with Aboriginal people, FASD prevention programs that can be delivered in a culturally appropriate manner.

34. We call upon the governments of Canada, the provinces, and territories to undertake reforms to the criminal justice system to better address the needs of offenders with Fetal Alcohol Spectrum Disorder (FASD), including: i. Providing increased community resources and powers for courts to ensure that FASD is properly diagnosed, and that appropriate community supports are in place for those with FASD. ii. Enacting statutory exemptions from mandatory minimum sentences of imprisonment for offenders affected by FASD. iii. Providing community, correctional, and parole resources to maximize the ability of people with FASD to live in the community. iv. Adopting appropriate 
evaluation mechanisms to measure the effectiveness of such programs and ensure community safety. (p. 4)

The impacts of the residential school system were and continue to be felt intergenerationally for Indigenous communities, families and individuals. Through the ongoing process of colonization, the residential school system was a pinnacle in the efforts and attempts of the Canadian government to dissolve Indigenous peoples' connections with their land, language, culture, identity, family and community (TRC, 2015). To provide further context of the legacy, St. Michael's Indian Residential School located on Treaty 6 territory, just outside of Duck Lake, Saskatchewan opened its doors in 1894 and was officially closed in 1996, marking it one of the last operating residential schools in the country (Niessen, 2017). Many families were never reunited with their children, their culture or their land thus continuing the intergenerational transmission of trauma (TRC, 2015). There is a direct link between substance use, trauma and the lasting impact of the residential school system on Indigenous communities, families and individuals (TRC, 2015). Salmon (2011) writes "alcohol use in pregnancy and the subsequent development of FASD can be seen as both a symptom and a legacy of the colonization of indigenous peoples in Canada..." (p. 171). FASD education and its supporting discourse thus needs to be placed within the social, cultural, and historical context of the ongoing colonization and legacy of the residential school system; in addition, this medical discourse on FASD needs to come from a strength-based perspective.

In a study examining eight FASD prevention programs from Indigenous communities and organizations across Canada, Wolfson et al. (2019), noted that all of the programs identified “reducing substance use in pregnancy and preventing FASD is not a women's or mental health issue, but a complex health and social justice concern requiring trauma-, culture-, and gender- 
informed responses at the individual, family, and community levels." (p.3). The eight FASD prevention programs contributed to a statement emphasizing that FASD health prevention should not have a primarily focus on the dangers of alcohol use during pregnancy but rather take a strengths-based approach by focusing on relationships, culture, and self-determination at the individual, family and community levels (Wolfson et al., 2019).

Gaps within the literature surrounding FASD include: minimal articles that center the voices of the biological parents of children with FASD; minimal articles that centre the voices of people with FASD; an absence of articles that discuss FASD as existing outside of the heteronormative binary; and a limited amount of articles that take a strengths based perspective that highlight the resilience of people with FASD in the face of such a stigmatized disability. The lack of these voices in the literature is evident in the way the discourse on FASD is presented, for these voices represent marginalized people and substance using women in particular are seen as "deviant and not as possessing knowledge worth listening to regarding their lives or mothering" (Brownstein-Evans, 2001, p. 168). This lack of representation contributes to the way that FASD is talked about and the roles and values assigned to the subjects in discussion of the texts and the framing of abstinence based messaging in pregnancy. This unidirectional way of representing FASD falls short on the full spectrum of information that can contribute to a better and fuller understanding of the disability and all who may be impacted by it. It is for this reason that this project is going to identify the social actors whom exist within public health campaigns on FASD, and explore how they are being represented based on the social practices of the medical field. The medical field currently dominates the discourse on FASD, which is troubling because at this point their representations are holding a monopoly on the beliefs and values of the dominant society. 
This literature review has explored a medicalized history of FASD as it relates to gender within the medical field. This review has examined the concept of stigma as it relates to both people with FASD and to mothers who are often the target of prevention campaigns. Finally, this review has examined the relationship between FASD and the TRC of Canada. This paper will now go forward to situate this research project within the theoretical framework of feminist theory and critical discourse analysis. In doing so, it seeks to ask the question of who is being represented by the current public health campaigns on FASD and how are they being represented. 


\section{CHAPTER 3. THEORETICAL FRAMEWORK}

This project situates itself within feminist theory, as women are central to the subject of

FASD. Women are constructed as being the cause of the FASD disability through medical discourse that is supportive of mother-blame. I want to apply a feminist perspective to this project as the current discursive practices on FASD fail to provide a depth to the social complexities of both the disability itself and the way that women are being constructed in relation to it. I am choosing to engage with the concepts of reflexivity, gender, and power, for these concepts are not only important to feminist theory but also to social work and CDA.

The act of reflexivity is an act of responsibility, bringing the relationship between researcher and researched into focus (Hesse-Biber, 2014). Social location is the examination of ones "gender, race/ethnicity, class, sexuality, age, religion and so forth [as] personal identities of difference and sites of social location and cultural diversity..." (Swigonski and Raheim, 2011, p.17). Identifying one's social location lays the foundation for reflexivity to occur as it places an individual's static and dynamic identities into question alongside their cultural and political environment. Identifying one's social location is imperative for exploring the relationship between the researcher and the researched, offering the context of how one's location influences and informs their unique interpretation of the research. The concepts of reflexivity and social location will continue to be explored in the methodology section of this paper.

Power and gender are both important concepts in relation to this research. Gender is a social construct that regularly engages in acts of power and subordination. Central to feminist perspectives is the understanding of patriarchy, the act of domination in which the female gender is constructed as being lesser than the male (Swigonski \& Raheim, 2011). When applying this perspective to the content of my analysis, I think about the ways that gender is influencing the 
public health messaging of FASD. Particularly I recognize the medical field as an institution embedded in male dominance and I especially recognize the construction of the female gender within this institution as being held responsible for any negative outcome of health measures. Both feminist theory and critical social work affirm that "everything has political elements: that is, nothing is neutral, everything involves struggle over power, resources and affirming identities" (Baines, 2007, p.51). This stance invokes the phrase that originated within feminist theory - "the personal is political" (Hanisch, 1970, p. 4) - solidifying the understanding that nothing is neutral, including gender.

Social work is a field that is heavily dominated by women; as a profession it has developed alongside the women's movement. Although the field is not directly or explicitly related to feminism, it is a field that is influenced by it (Swigonski \& Raheim, 2011). While gathering relevant articles on feminist theory, the disconnect felt between feminism and social work created a barrier for me while trying to conceptualize their connection. This barrier could be because there are limited articles from both fields of feminist theory and social work that discuss their connection. This phenomenon has also been noted by Gringari, Wahab and Anderson-Nate (2010), who write:

Despite the existence of feminist social work practice, courses on feminist research methods in schools of social work, and specific journals and researchers dedicated to "women in social work," social work is curiously and strikingly absent from broader multidisciplinary discussions and explorations of feminist research. (p. 390) When discussing the concepts of gender and power in relation to both social work and feminist theory, I want to acknowledge and state my position. I do not believe in essentialized definitions of gender. For me, this means that I do not accept the belief that a person's sex and 
gender are synonymous and that their gender is discounted if it does not match their sex assigned at birth. As a non-binary person, this is important for me to state as there is no universal definition of what feminist research is. I have observed that there are many researchers in the fields of feminist studies and social work that subscribe to the notions of essentialized gender presented by second wave feminism. It has been interesting for me to explore this project as a non-binary person as the gathered content (from the literature review on FASD to the corpus selected for analysis) is exclusively rooted in heterosexual and cisgender constructs. This way of thinking erases LGBTQ identities, inclusive of my own, as it operates under the assumption that only cisgender and heterosexual women are able to conceive children that are impacted by prenatal substance use.

\section{Critical Discourse Analysis}

CDA is interdisciplinary in nature due to its applicability within a variety of fields and its social, cultural, and ideological components. Meyers (2001) sees CDA as part of a hermeneutic circle which "implies that the meaning of one part can only be understood in the context of the whole... (which) is only accessible from its component parts." (p.16). When we break down the components of CDA to render it whole we can see that discourse is: "a patterned system of texts, messages, talk, dialogue, or conversation which can be identified in communications" (Lupton, 1992, p.145) and when discourse is analyzed using the context in which those systems of communications exist, different theories can be applied to make meaning out of the whole. A wide variety of different perspectives and theories can be applied to CDA creating a continuous loop of analysis (Meyers, 2001), suggesting that another researcher could duplicate this study applying a different theory, and as such get different results, for this study is accounting for one particular temporal perspective. One example of the wide applicability of CDA which is relevant 
to my study is Lazars' (2007) feminist approach to CDA “which aims to advance a rich and nuanced understanding of the complex workings of power and ideology in discourse in sustaining (hierarchically) gendered social arrangements." (p.141). Lazar situates CDA within feminist theory to draw upon themes of gender ideology, patriarchy and power as well as the need for reflexivity and social change in practice (2007). Gringeri et al. (2010) discuss that within feminist research is the belief "that conventional science functions within a maledominated paradigm [which] produces an androcentric bias in science.” (392).

The current health promotion/prevention campaigns on FASD lie within a maledominated paradigm where the target is pregnant women, with the goal of a healthy child which is surrounded by discourse informed by biomedics and evidence-based practice (EBP). At the center of EBP is logic, objectivity, rational choices, and effectiveness (Bates, 2011) which are all male dominated areas of thought (Hesse-Biber, 2014). The problem with an EBP is that it omits other ways of knowing (stories, personal experience, knowledge passed down through generations) which are crucial for the knowledge sharing with and among women. This is important because the current mother-blaming discourse on FASD constructs women as being unable to make the right choices for their bodies and are expected to prioritize the unborn/born over their own wellbeing.

CDA has "the potential to reveal valuable insights into the social and political contexts in which varied discourses about health take place." (Lupton, 1992, p. 146), and if health promotion practitioners were to apply reflexivity to their work perhaps the discourse around it would start to change. As noted by Tretheway, Taylor, O’Hara and Percival (2015) in their article about the importance of critical reflection in health promotion they offer this wisdom: "Applying reflection to critical health promotion means considering the broader structural determinants of health that 
go beyond individual behaviours. Therefore, critical reflection presents a challenge to traditional health promotion approaches that are underpinned by biomedical and behavioural health discourses" (p. 217).

Feminist theory and CDA both aim to reveal that power exists behind all exchanges. CDA, like feminist theory, is interested in the social and political contexts of subjects, to make sense of the whole picture by looking at its parts. The union of a feminist approach to CDA allows for an exploration of discursive practices as they relate to power, gender and ideology as situated within systems of male dominance, or for the case of this paper, situated in the system of health sciences. Framing my research to be housed within feminist theory, and identifying that I will be conducting a critical discourse analysis I will be exploring the concepts of gender, power, ideology and reflexivity to help guide the analysis. We will now continue onto the methodology section where the research question, aim for the study, and tools for conducting my analysis will be discussed. 


\section{CHAPTER 4. METHODOLOGY}

This study applies a feminist approach to CDA in efforts to produce an analysis in connection to the representations of social actors in FASD targeted health prevention/health promotion campaigns. This chapter is going to walk through the research question, the method for collecting data, and tools I have chosen to analyze that data.

\section{Purpose of this Study}

This study aims to identify and challenge the current perspective of how people are being represented not only in FASD campaigns, but also in the discursive practices of the healthcare system, predominantly found in public health. The question central to this study is: Who are the social actors involved in health promotion campaigns targeting FASD and how are these social actors being represented through the lens of CDA and feminist theory?

\section{Corpus Sample and Method of Data Collection}

The process in which I chose which campaigns to use for my analysis began with a simple Google image search of "FASD Campaigns in Canada" which pulled up many pages worth of pictures depicting a common theme of fetuses consuming the alcohol that the mother is drinking, men cradling babies, and headless shots of women's bodies focused on the pregnant belly. When sifting through these campaigns, the ones that I ultimately chose I had personally seen myself posted in my community of Saskatoon, Saskatchewan. Choosing campaigns that are situated within my geographical location helps to situate myself, as researcher, into the project. Sharing the geographical location of my study is important in that it gives context to the social and relational environment I am engaging with. The other reason for choosing these three campaigns are that they are relatively recent; the posters are currently on display in the community and based on publication dates, they have all been created since 2015 . 
I chose three campaigns (text and visuals) that were diverse in image, created by a health prevention or promotion group, and were inclusive of the main images being portrayed by the general initial search of "FASD Campaigns in Canada". I acknowledge that this is a small sample size, and that with more campaigns I would be able to create a more holistic and robust analysis; however, for the purposes of this paper I feel that three campaigns are sufficient due to the time restraints of a graduate project and my capacity as an inexperienced researcher to explore a corpus that is of manageable size.

\section{Method of Data Analysis}

I will be applying van Leewen's (2008) approach to social actors within CDA, produced through both text and visual representations as tools to answer the questions I have posted above. As this study is examining health prevention/promotion campaigns, there is a merging of image and text to create an all encompassing visual rich in meaning and context (van Leeuwen, 2008).

This study is examining the representations of social actors (the meaning of which is synonymous with participants) as depicted by the medical field's practice of creating public health promotional/prevention_based campaigns targeting FASD. Van Leeuwen and Kress (2005) explain representations of social actors as "the subject matter of the communication; that is, the people, places, and things represented in and by the speech or writing or image, the participants about whom or which we are speaking or writing or producing images" (2005, p. 48). Representations place social actors in relation to their roles within social practices, defined as: "socially regulated ways of doing things" (van Leeuwen, 2008, p. 6). As a representation, the social actor has no autonomy in how they are being depicted, as this is done through the creator or writer's interpretation of their role and attributes. 
Van Leeuwen (2008) explains that "Linguists tend towards preserving the unity of formal categories. I shall here attempt the opposite approach, hoping to provide a set of relevant categories for investigating the representation of social actors in discourse.” (p.2) In this quote van Leeuwen is situating the representation of social actors in CDA. He is deepening the connection from studying the semantics of a word or set of words, to situating them within a context that gives them power and meaning. Van Leeuwen offers a set of categories to describe how social actors are recontextualized or represented in relation to social practices. This study is going to apply three of the main categories proposed by van Leeuwan in relation to my corpus including: Inclusion and Exclusion, Functionalization and Identification, and Personalization and Impersonalization.

The former categories were chosen for their applicability to feminist research in relation to the medical system. The three categories have the potential to peel back the layers and view the power dynamics at play within the public health campaigns. A quick overview of the images analyzed for this study suggests that women are often backgrounded or excluded as women, are only given value for their role and function in their reproductive ability, and are often depicted as an object rather than a human being. Applying these three categories, to identify how social actors are being represented, may open the door to then shifting those representations to be more inclusive and valuing of the people depicted by the current messaging.

\section{Categories of Representation}

Inclusion and Exclusion. Van Leeuwen explains, "Representations include or exclude social actors to suit [the writers'] interests and purposes in relation to the readers for whom they are intended.” (2008, p. 28). Some exclusions may be innocent in nature, and others are seen as strategic exclusions in order to persuade the reader to adopt a certain ideology or view of the 
social actor. Backgrounding is a type of exclusion that occurs when a social actor is "not so much excluded as deemphasized" (van Leeuwen, 2008, p. 29). Backgrounding alludes to the social actor being situated within the image or text somewhere but may not be made directly aware to the reader. While those who are excluded may not be made explicit to the readers of the representations, the decision for who to include is made implicit through the composition of the text/visual representation of the social actor. This is done in practices such as who is foregrounded, who is centered in the image, and what angle is used to present them.

Personalized and Impersonalized. There can be personalized and impersonalized representations of social actors. When a social actor is personalized, they are being represented as human beings through personal pronouns, proper names, or any other semantic feature that depicts a 'human' (van Leeuwen, 2008). Impersonalization on the other hand, has the opposite effect where a social actor is being represented more as a non-human subject through the processes of abstraction. Abstraction occurs as a method of representation in which a person (or social actor) is identified based on a quality that is assigned to them; thus, a person becomes that abstracted identity, such as an alcoholic, a problem, or a victim. (van Leewen, 2008). Objectification in this context relates to representation through the means of an association to a place or thing relating to an activity in which a person is engaging (van Leeuwen, 2008). Important to this study is somatization which falls under the category of objectification. Somatization refers to a social actor being represented in terms of reference to a body part (van Leeuwen, 2008).

Functionalization and Identification. Functionalization refers to the process in which social actors are referred to in the context of what they do (role, occupation, activity). Identification occurs when social actors are represented not by what they do but what they are 
(van Leeuwen, 2008). Functionalization is more or less of an impermanent attribute or role while identification is associated more or less with a permanent fixed identity (van Leeuwen, 2008). Historically and culturally speaking, both terms (functionalization and identification) can and have shifted from one term to the other in time (van Leeuwen, 2008). An example of this can be found within substance use, wherein a person may be referred to as a social drinker and then identified as an alcoholic which to some is an identity that is static and to others it can shift over time. One of the subcategories within identification that is relevant to my study is relational identification which "represents social actors in terms of their personal, kinship or work relations to each other..." (van Leeuwen, 2008, p. 43).

\section{Reflexivity}

"Feminist research practitioners pay attention to reflexivity, a process whereby researchers recognize, examine, and understand how their social background, location, and assumptions affect their research practice.” (Hesse-Biber, 2012, p. 21) Reflexivity is a concept that is congruent with feminist theory, critical social work, and critical discourse analysis. It is at this point that I (the researcher) will offer my relationship to this project in efforts to ground my knowledge and assumptions, and give you, the reader, an opportunity to spot and situate my bias within the content of the analysis. In addition to the quote above, I will include words by Lupton, for her contributions to discourse analysis have helped form my understanding of it within a male-dominated medical context: "The role of discourse analysis as a critical tool requires that the commentators' particular perspective be made explicit” (1992, p. 148).

I am positioning myself as a social worker as one integral part of this project, the other part is in identifying my social location and emotional/spiritual attachment to my relationship with this research. I grew up in Saskatchewan and come from a working-class background, I 
identify dynamically as queer, non-binary, and working class while statically identifying as a white settler. Within the past year I have been working as a program developer and facilitator with an organization that supports people with FASD and their families. I am a bio-child of a foster home and am used to different professional identities entering my family's house with their own perspectives on how to manage the home, as if it were a public place. I regularly saw social workers and health workers engage with the home as if it were a toxic environment with one perspective engaged with the well-being of the child and the other perspective engaged with the well-being of the public, and both perspectives active in surveillance. In addition to these experiences, two of the children that I grew up with have a diagnosis of FASD.

As I enter into the analysis chapter of this research paper, how I define myself and the way that I relate to the subject of this paper will inevitably bleed through parts of the analysis. 


\section{CHAPTER 5. ANALYSIS}

Using feminist theory, CDA and social work as my framework for understanding, this chapter is going to outline the many social actors found within the health promotional campaigns targeting FASD (visuals: text and image) and explore the ways that these social actors are being represented (or depicted) using the categories provided by van Leeuwen (2008). The three campaigns are included as appendices to this MRP. The social actors found within the campaigns include: The sayer; the reader; the unborn/born; the mother/women; the father/men; people with FASD. This analysis will now go through each of the listed social actors, followed by a discussion of the findings.

\section{The sayer}

Campaigns are built on visuals, visuals that illustrate a reality bound to the interests of institutions that produce, circulate and read them; making them ideological (Kress \& van Leeuwen, 2005). The sayer is both an interactive participant and actively engaged actor in the representation of oneself (views, beliefs, ideology). In a visual the sayer is the one "from whom the dialogue balloon emanates" (Kress \& van Leeuwen, 2005, p. 75). In the context of these three campaigns, the sayer is not only the voice of the campaigns, it also is the power, authority, and conviction presenting itself persuasively through utterances. Utterances are the sharing of views and beliefs about the participant who is the subject of the dialogue balloon being presented to the reader (Kress \& van Leeuwen, 2005). In the three campaigns I examined, the sayer was represented through the agency branding of the Saskatchewan Prevention Institute (SPI) and the Alberta Gaming, Liquor and Cannabis (AGLC) and as agencies they are the actors behind the public health informed campaigns. The role of public health informed messaging is in a sense to protect people from harm, and it has the authority over society to put trust in its messaging. 
Health elitism is at the core of that messaging for public health creates policies that reflect what they think is in the best interest of society, when they may not even have a grasp of the needs of people outside of a health context. Public health and government agencies rely on mass campaigns to get the information out to the public, and they make choices as to how that message is going to be produced and read based on their interests and realities. For them, it may seem logical and attainable to abstain from substance use while for others that is not a possibility. The sayer framed by CDA is involved with the power and dominance being reproduced in their messages; further framed by feminist theory, the sayer is perpetuating stigma, misogyny and gender-based violence against women. This is found in how women are objectified in their campaigns through somatization, making reference to them based on parts of their body. For example, in campaign \#1, a woman's reproductive system and uterus are the focus, and then are excluded from all other campaigns while prominently featuring men in positions of calmness and care (see campaign \#2). In the third campaign, the sayer is represented in a dictionary-style approach, where there is a visual definition of the word 'tertogen'; the use of this dictionary approach reflects an impersonal voice of authority. The sayer is also represented visually, behind the dinosaur, apparently causing an expression of fear in the dinosaur; in this way, the sayer is not only responsible for the delivery of the information but is also responsible for the reaction given by the dinosaur, which will be discussed further in the category below. The sayer, as a representative of public health messaging has the unique position of social power where, through discourse presented visually on the health promotion campaigns, they are able to reach and pull in the attention of the reader. 


\section{The reader}

Campaigns are a significant agent in socialization, and visual imagery can have a powerful impact on our attitudes, values, beliefs, and behaviours even to the extent of how we view gender and gender relations (Goffman, 1979). As the reader of the campaigns and recipient to the message it conveys, you are both an interactive participant and a represented social actor. This example is made clear through the first campaign which states "When you drink, they drink", where you are being invited to identify with the you in the image. This image and construction of you as a potentially pregnant person, constituting the subject matter of the campaign; equally, you are remaining an interactive participant by being a voyeur to an intimate moment, an ultrasound image of a person's uterus, and deciding which side of society you fall on: one of us (the sayers) or one of them (social deviants). The invitation almost gives you an ultimatum of being shamed or of joining in for the public shaming and educating of women choosing to consume substances. This ultimatum is presented a second time in the third campaign where the reaction of the dinosaur is being used as an agent of socialization, showing you the appropriate reaction to mirror or to emote when confronted with the information of alcohol consumption during pregnancy (van Leeuwen, 2008). Additionally, it seems you are being asked either to join in on the shaming of the dinosaur, thus removing yourself as the subject of speculation, or to internalize the dinosaur's reaction, by being shamed yourself. The emotions displayed by the dinosaur could be perceived as fear, bewilderment, or shock. Determining the exact emotion being displayed is subjective; however, it is clear that the emotion to mirror when confronted with the subject of substance use in pregnancy is one founded in shame. 
In comparison to the conflicted feelings grounded in the campaigns \#1 and \#3, we see a soothing invitation of engagement with the second campaign featuring a father and his child, wherein the reader is invited to gaze at the intimate exchange between the two subjects of the image offering you, the reader, a glimpse at their loving bond. This second campaign is one which requires little of your concern, as juxtaposed to the warnings presented in the first campaign which displays harm to the unborn by way of maternal-fetal alcohol bonding. Both campaigns \#1 and \#2 classify and represent the parental responsibility in keeping the infant safe, and as a viewer you are being persuaded to see each social actor in a specific light with their behaviours given a specific weight. The warm tones in the visuals of father and child, or the stark and abrasive image of mother and fetus reinforce these differences.

\section{The unborn/born}

The infant as shown in campaign $\# 2$ is synonymous with the fetus/unborn presented in campaign \#1, both of which are being represented as the goal of the campaigns. A goal, according to Kress and van Leeuwen (2005) is the "passive participant in an action process... is the participant at which the vector (action) is directed" (p. 74). A passivated actor is represented as a social actor having an action done unto them. This is illustrated as the passing of alcohol (a teratogen, campaign \#3) between mother and the unborn or developing fetus (campaign \#1). In the campaigns \#1 and \#2, the infant or the fetus is being represented as an object in an exchange, an exchange between mother and father (\#2) and an exchange between mother and society (\#1) with the ultimate goal being purity in reproduction. Campaign \# 2 can be seen as reproducing a sense of purity of the child, with an image of a child who is white, blonde, and untainted by a disability. 
The unborn is given the status of personhood (campaign \#1) through the personalization of human characteristics: the use of the pronoun they and the superimposed beer bottle placed in the hand of the fetus implies that they too are able to hold material items found outside of the womb. In Campaign \#3, the unborn is represented by the colour scheme using a nursery room pastel purple, the choice of using an illustration or cartoon caricature of a dinosaur, and the utterance of the words "unborn baby" in the definition, in relation to alcohol as a teratogen that can cause harm. The child however, and any blatantly exposed social actors are removed from the image, offering it a simplicity reminiscent of a child's book. Although the composition of the image is presented in a child like tone, the context of the message and the socialization of expected reactions to display when learning of alcohol consumption is heavy in meaning. The visuals give permission to watch and surveil a woman to ensure the protection of the unborn, for the expected reaction is one rooted in negativity. Through the discourses provided in the three campaigns, we start to see the value being placed on the fetus over the mother; one worthy of protection, and the other worthy of scrutiny and surveillance.

\section{The mother/women}

The discovery of toxins passing freely between pregnant women and the unborn marked the discourse of responsibility between the unborn and a maternal body for it drew attention to the medical worlds perception that whatever a woman consumes can pose a threat to the fetus (Lupton, 2013). What you see in campaign \#1 is an example of this discourse in action. While maintaining that the unborn is the goal in the transaction, the campaign brings a harrowing feeling of wrongdoing with the false sense of agency to choose between alcohol or the baby, implying that to choose alcohol is to step on the wrong side of medicine. The beer bottle being consumed by the fetus is being used as the vector in the image, the vector being a directional 
element connecting an actor to a goal (Kress \& van Leeuwen, 2005). This is done by depicting that the maternal person's choice to consume alcohol is directly affecting the purity of the child which is more important than the maternal person's self determination regarding the consumption of alcohol.

The representation of the mother's role or function in both campaign \#1 and campaign \#2 is to focus on the wellbeing of the child, even at the detriment of the mother herself. This is highlighted through the words "When you drink, they drink" and "There is no safe amount and no safe time to consume alcohol" (campaign \#1), "I supported her not to drink" and "Alcohol can harm an unborn baby" (campaign \#2), and "alcohol is a teratogen, a substance that can harm an unborn baby" (campaign \#3). All of these words are in effort to support the baby, and none of them are demonstrating any support to the woman or pregnant person outside of concern for the purity of the child. The maternal body is being represented within the campaigns and the rest of her is backgrounded throughout it all, as she is never seen or heard in the campaigns.

The campaigns are representing a one-dimensional quality to women, as if to conclude that women, once pregnant, are no longer complex beings and have one simple directive to follow: do not harm the baby. In the second campaign, women are portrayed as being dependent on their male counterpart in supporting her not to drink, suggesting that without his aid, who knows what terrible decisions she is able to make. In the third campaign, the dinosaur is represented as a deviation of the mother/woman. van Leeuwen (2008) states that a deviation occurs when a "social actor is being represented by another social actor who would not normally be eligible to partake in certain activities" (p. 50). An example of a deviation is when a person is replaced by an animal or fictional character that then carries out the persons social activity. A deviation is used to solidify that the "failure of the deviant social actor confirms the norms" of 
society (van Leeuwen, 2008, p. 51). Thus, the reaction of the dinosaur is the reaction of the woman/mother who is caught in her failed attempts to stay away from substances during pregnancy, confirming that an abstinence-based model during pregnancy must be the norm. The narrative told in the second campaign is that of passive actor deletion: once the goal has been met of the maternal delivery of a healthy child, the child is then given to the father for safekeeping and the woman is quite literally nowhere in the picture.

In the first campaign, the woman is being represented through an internal image of her body, the ultrasound; this image is an impersonalization where the woman is rendered to representation based on her reproductive system. Through these images I have drawn the conclusion that the woman is only being represented based on her function as child bearer and her relational identity as mother to the child. None of the campaigns center women or their experiences.

\section{The father/men}

In campaign \#2 we see the role of the man being represented as both a passivated beneficialized social actor and an activated circumstantialized social actor. He fits into the category of being a beneficialized social actor due to his position of begetting the child, for a beneficialized social actor is a third party on the receiving end of an action which can be viewed as an acquisition that is positive or negative in exchange (van Leeuwen, 2008). The man is simultaneously being represented as a circumstantialized actor. A circumstantialized actor is one whom is galvanized from their status as a passive actor to an active one due to the materialized event (van Leeuwen, 2008); the situation triggering his activation is his need to support his potential offspring by ensuring the maternal carrier abstains from consuming alcohol during the 
pregnancy, thus removing or dissociating the woman from her connection by having her backgrounded through text on the image.

The man is foregrounded in the campaign, both visually and textually as he takes on the role of the sayer through first person language, "I supported her not to drink". The visuals include the infant being safe and sound in his hands, attributing his support of the mother's alcohol-free pregnancy to the child's healthy status. This suggests that without his support the child would be born tainted by the maternal carrier's alcohol consumption, placing the father to be viewed as the hero for he has saved the child from the harms of the mother. The hero is a common archetype perpetrated in the medical field and other male dominated professions which values masculine traits such as technical skill, logic and action (masculine traits) and then devalues feminine traits such as emotionality and relationship building (Ainsworth \& Flanagan, 2019; Sharma, 2019). This could be why the father in the second campaign is constructed as a hero, for that archetype only exists in this narrative through the devaluing of the mother who is included in the campaign by virtue of possible harms she can cause. The second campaign opens up an analysis of gender in the juxtaposition of the man being featured using first person language, using his own voice (campaign \#2), and the woman being represented through the voice of the sayer (campaign \#1) and not given the tools to express her own role. The woman is presented as a passivated actor (campaign \#2) in that she needs monitoring (surveillance) and support from the man in order to make good decisions and not harm his child. Once that support is given and the child is born without a disability, the woman is quite literally out of the picture.

The holding and caressing of the child by the father in the second campaign contributes to a type of possessiveness demonstrated between the association of father and child (over mother and child) being more stable, and safe (van Leeuwen, 2008), dissociating the pregnant 
person from her stats as belonging within the relational kinship and role as mother or care provider. Halliday (in van Leeuwan, 2008) says that association may be realized by "circumstances of accompaniment" (p. 39); this rings true in this image for there were circumstances (pregnancy) that allotted the woman to participate and associate with the group. Once the role is over (birth), the circumstances have changed and she is no longer needed. The child as a goal, is born with no sign of harm meaning that the father is begetting a child free from disability.

If we relate this back to the introductory chapter of this MRP, there is a similarity in the discourse of the post-mortem infant found in a bin. "Next time, come to us, we will take care of the child" is offered, with little discussion on how to provide care for the woman. In the case of the Calgary woman, she is found, arrested and charged as that is presumably the only way the system knows how to support society - by removing the threat. The social distance between us and the father/baby is a close up at eye level. In pictures, "people shown in a 'close up' are shown as if they are 'one of us'"' (van Leeuwen, 2008, p. 138); thus, the father and the baby are shown to be one of us, while the omission of the woman in the picture shows her to be not part of the trio or now dissociated from her association with the fetus as it is now a baby safely in the care of the father.

\section{People with FASD}

People with FASD are excluded from the conversations made about them; in all three campaigns the message being portrayed is how not to have a child with FASD and in the literature review the biomedical and public health discourse is focused on what happened to cause FASD with little support being offered for the folks that are actually living with the disability. People with FASD are being represented within these campaigns as victims of the 
good versus bad behaviour of their maternal carrier. With the goal of the pregnancy being to reproduce a child free from imperfections, what then does that say in relation to children born with a disability, and more so, how their carriers then are perceived as not caring for them?

In the first campaign, a child with FASD is being described as suffering a life-long condition with no cure, complete with birth defects, nervous system disabilities and permanent brain damage. This type of discourse highlights the potentially life altering effects of someone who does not fall along the normative axis of health from a biomedical perspective, rather than a strengths-based approach highlighting support for the child, and ultimately the mother, who may not be offered the privilege of a no-harm birth.

People with FASD are presented in much the same light as a woman with substance dependence - as damaged goods. The aim of the campaigns is to prevent this disability from happening, and casts a light of shame unto both child and mother. People with FASD are not only excluded as valuable members with valuable perspectives in these campaigns, they are being omitted to help solidify the culture of fear that surrounds them. 


\section{CHAPTER 6. DISCUSSION}

The current discourse on FASD being presented by the medical system is rife with stigma and blame. This research set out to explore the representations of people found in public health campaigns in an effort to challenge those discursive practices that support the naming and shaming of maternal carriers who consume alcohol. What I found was the identification of six different social actors within the campaigns. Three of these social actors were explicitly portrayed: The mother/women; The father/men; the born/unborn; three of these social actors were not made visible to the campaigns but were present nonetheless: The sayer; The reader and people with FASD. The results of the analysis were successful in demonstrating the representations made of each actor and how their roles in relation to FASD are depicted by the healthcare system. The following paragraphs will discuss the main points identified through the analysis and relate them back to the content explored within the literature review, and other areas of this paper.

\section{The medical system}

As previously noted, the medical field is rooted in male dominance (Gringari et al, 2010; Sharma, 2019) The results of my study indicate that the actors responsible in the creation of the campaigns are using the voice of the sayer, a social actor, to deliver the beliefs, values and ideologies of the medical system. The public health campaigns are used as a template in which to persuade the readers of the campaigns to adopt and internalize the views being presented, even if the views run in opposition of their intended objective of prevention. The objective of prevention is found to be achieved in the campaigns as demonstrated through the visuals of the campaigns in which the harm alcohol poses to the unborn by way of maternal consumption is highlighted, and that abstinence from substances is the ultimate goal in achieving prevention. This abstinence- 
based discourse, however, frames women who consume substances as being "bad" for the message is that their consumption is directly linked to causing FASD. This messaging has been stated as harmful in perpetuating the stigma of mothers who consume substances as it may result in their reluctance to disclose alcohol use to health care professionals, or others as they don't want to be stigmatized as being a bad mothers (Chaote \& Badry, 2019; Salmon, 2011; Zizzo \& Racine, 2017). The stigmatizing messaging may be directly related to the observations made that there is low engagement between public health and the public on the topic of FASD (Corrigan et al., 2018; Gonzales et al., 2018) and the messaging may be compacting the distrust felt in the medical community for they are continuing to perpetuate the dominant male ideologies already found within their practice. This perpetuation of dominant male ideologies is shown in the way that women are are represented in the campaigns on FASD through gendered roles and assumptions.

In all three campaigns women/mothers were backgrounded thus never quite seen or heard but made reference to based on her their role of reproduction and function to deliver a healthy baby to the father, the ultimate goal of the campaigns. The backgrounding of women/mothers is done to bring forward the ideals of the patriarchal medical system by silencing the experiences of women that could have been included to ground the messaging of the campaigns in context and understanding. The perpetuation of patriarchal views that prioritize medical knowledge, such as knowledge that is objective, rational and evidence based, creates barriers for critical and feminist perspectives to exist within them (Sharma, 2019) because there leaves little room for the subjective experience of a person who does not fit the mould of the good mother. The idealized view of a good mother was explored in the literature review as a maternal figure that upholds strict virtues that were created by a male dominated system and perpetuated in the medical 
community, and the image of a woman who consumes substances is viewed as the opposite of this idealized standard (Brownstein-Evans, 2001); this concept of a woman who uses substances as being the antithesis of a good mother could be why the campaigns are so heavy in emoting shame; shame of the person who chooses to consume, and shame of the person who chooses to not shame the person who consumes. To shift the message on shame found in the medical discourse of FASD the creators of the campaigns or the medical system would need to shift their view of the idealized good mother and accept the variations of good and bad that exists in a person whether or not they choose to consume substances. The omission of women's voices in particular who choose to consume alcohol is sorely missing from both the literature on FASD and in these campaigns.

The father in these campaigns is represented in much of the same light as the idealized good mother, but instead is rooted in patriarchal ideologies that show him to exude calm, rational, logical, and authoritative qualities found in the depiction of the health care system itself. The father thus is complicit in the messaging of the health care system that women need to be under surveillance and told what is good for them, this is found in the campaigns through the authoritative voice of the sayer in which all of the studied campaigns contain. The healthcare system is given the authority to lead the discourse on FASD because as a society we are told to put our trust in that system, which is positioned to protect the public from harm. However, as discussed in the theoretical framework the health care system struggles to incorporate reflexivity in its practice (Tretheway et al., 2015). This lack of reflection is shown in the campaigns for the father is presented as embodying the virtue of being "good" (active in the role of caring for the child) and the mother is reflected as embodying the virtue of being "bad" (needing surveillance to ensure she not consume alcohol) the combination of which supports binary thinking and does 
not acknowledge that the father/healthcare system may be complicit in the harm caused unto the woman. The framing of the father/medical system as the entities embodying what is "good" is largely ego boosting and paternalistic as it assumes no responsibility for potentially being a contributing factor of the 'problem'. This issue of the medical system being seen as lacking reflexivity and the insight of possibly contributing to a problem, is especially relevant in relation to power dynamics as seen in its adoption of the term social determinants of health.

Social determinants of health refers to the "conditions in which people are born, grow, live, work and age" (WHO, 2013, para 1) which seems like the external version of social location a term which previously explored is supported by social work and feminist research in which a person identifies within themselves their various occupations along the same continuum. The exercise of identifying one's social location or identifying another's social determinants of health only serves to view one side of an interaction, without the piece of critical reflection, a person (or in this case a profession) is removing itself as existing within the power structures inherent to any relationship. I feel that the lack of reflexivity applied to the campaigns on FASD and to the discourse of blame presented through the health care system is the reason why these campaigns feel stuck in traditional gender binaries and roles for: "self-reflection is conceptualized as a search for ways to interact with the other which opens the relationship for new possibilities of discourse" (Miehls \& Moffat, 2000, p. 342). Without an understanding of the ways that the health care system is complicit in perpetuating the power dynamics in which women do not feel comfortable seeking help or disclosing their truths, accurate representations of the complexities women face will continue to be excluded from their messaging. 


\section{The portrayal of women and people with FASD}

The results of the analysis confirmed what was discussed in the literature review: the identification of maternal substance use during pregnancy and people born with FASD are both highly stigmatized subjects or identities. Stigma, as discussed by Goffman (2006), works to create a discrediting and/or tainting view of an individual or group. This discrediting is shown through the omission of FASD identities in the literature review and in the campaigns, we see this in the representations of people with FASD as being victims to the poor decisions in substance use by their maternal carriers. The portrayal of a stigmatized group contributes to an "othering" where "complex social problems are assigned and attributed to the failings of certain people" (Seymour, 2015, p. 281). This contributes to the dichotomies of us/them. With respect to the campaigns, these dichotomies include good mother/bad mother, tainted/pure, and that which was discussed in the introductory chapter, victim/perpetrator.

These dichotomies were demonstrated in the results of the analysis. When comparing them to the lack of trust in the medical system identified in the literature review, we can see the binary thinking of women as good or bad. This binary perpetuates the stigma of undesirable behaviours such as alcohol use in pregnancy and simplifies the complex realities that women are experiencing.

As noted within the literature review, and again in the section above there is low public engagement with the current public health messaging on FASD (Corrigan et al., 2018; Gonzales et al., 2018). Through the work I have done on the analysis of these campaigns, I would like to further add another perspective to the discussion of low-engagement. I suggest that the low engagement is connected to people not seeing themselves accurately represented within the campaigns, which is inherently problematic. Being confronted by the current depictions actively 
being displayed out in the community can be anxiety provoking and uncomfortable as many people have experienced, either directly or indirectly through their intimate relationships, the intersections of pregnancy, substance use, and gender-based violence (Wakoma, Jampala, Bexhell, Guthrie \& Lindow, 2014). The omission of lived experience felt by those who have navigated the intersections of pregnancy and substance use is in itself an act of gender-based violence, for the failure to include their voices contributes to the objectification, somatization and ultimate dehumanization of woman choosing to consume substances while pregnant. The exclusion of those experiences is directly related to lack of depth and understanding of the people represented within the campaigns, and as such found within the healthcare system.

\section{Strengths, Limitations and areas for future study}

A strength of my paper being situated within CDA with the understanding offered by Meyers (2001) is that in order to see the whole picture, you must examine the parts, which is what was done here. By breaking apart the campaigns and assigning names/attributes to the social actors found within them, I was able to get a deeper understanding of how those actors are being represented, More importantly, I uncovered how those actors are actively constructed out of the values, beliefs and ideologies shared through the medical industry/public health.

The limitations of this research is found in the small corpus of campaigns selected to analyze, and in the application of one particular perspective (my own) in creating meaning out of the content using a feminist approach to research in CDA, with the application of CDA within this field being used by multiple theories and perspectives the discourse on FASD has strong potential to shift course and house itself within an understanding of the complexities people of all genders face in relation to the consumption of alcohol or other substances during pregnancy. 
An area of exploration I would like to explicitly highlight as a site for future research is in the experiences of substance use and pregnancy found within the LGBTQ2S community, for this could add a depth to the conversation and offer an alternative to the current heteronormative construct of FASD and substance use. This inclusion could aid in the creation of a new way to talk about this issue by using a different lens. 


\section{CHAPTER 7. CONCLUSION}

There are so many varied public health campaigns out in the community, and while this project focused on one narrowed targeted campaign issue, FASD, the ways that people are being represented within their campaigns needs to come to the forefront of reflexivity to engage in ways people can be represented that is not harmful or stigmatizing, given that these approaches could be causing people to turn away from those messages. With this research paper I set forth to explore the dominant discourse of mother-blame privileged in health sciences as it relates to FASD and hoped to disrupt that discourse by making room for other perspectives. As public health continues to expand their work from biomedicine that is inclusive of social issues including social determinants of health, I think they need to think critically about the discourse that is currently being used. It is time to start including the voices of lived experience, to drop the dichotomy of good vs bad behaviours, and stay away from abstinence-based messaging. Public health could use a practice of reflexivity as demonstrated in both social work and feminist theory to start using campaigns targeting their own institution's level of awareness of the harm they cause by representing individuals, families and communities as anything less than the complex, resilient and capable people that they are. 


\section{Appendix A: Campaign \#1}

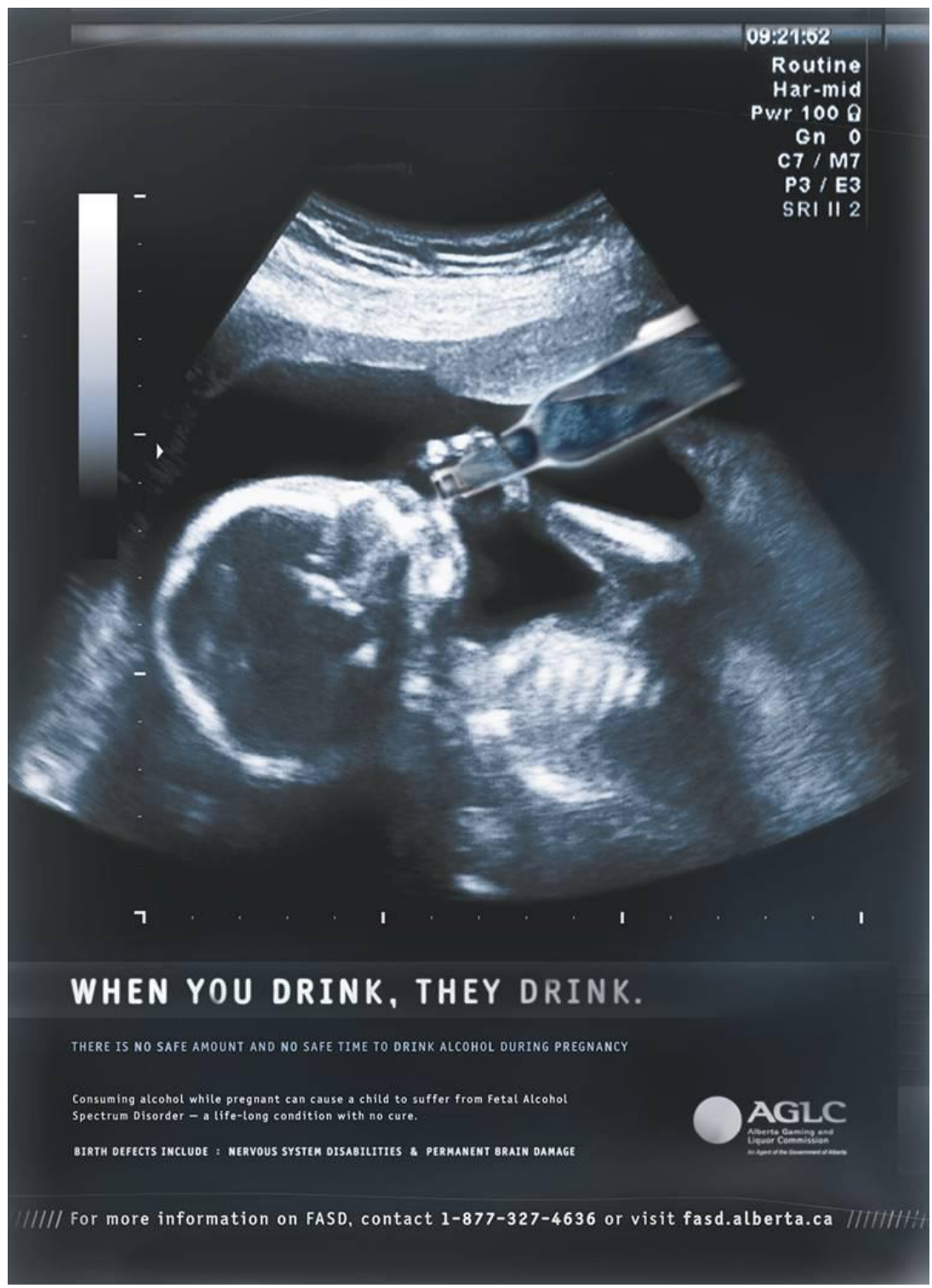

\section{When You Drink, They Drink (2013)}

Campaign accessed from: http://fasd.alberta.ca/aglc-poster-campaign.aspx

Image Description: An enhanced ultrasound image of a late stage fetus in utero, the image has been altered to include a bottle, presumably a beer bottle, being held by the fetus in an upright position to imply the fetus is drinking from the bottle. The main text is embedded within the image, below the fetus that reads: When you Drink, They Drink. In smaller font the text reads: 
There is no safe amount and no safe time to drink during pregnancy. Below this text in smaller font it reads: Consuming alcohol while pregnant can cause a child to suffer from Fetal Alcohol Spectrum Disorder - A life-long condition with no cure. The poster contains a logo from the Alberta Liquor Gaming Cannabis (ALGC) and includes the telephone number and website for the fasd.alberta.ca. The image uses gray-scale colour schematics. End I.D.I 


\section{Appendix: Campaign \#2}

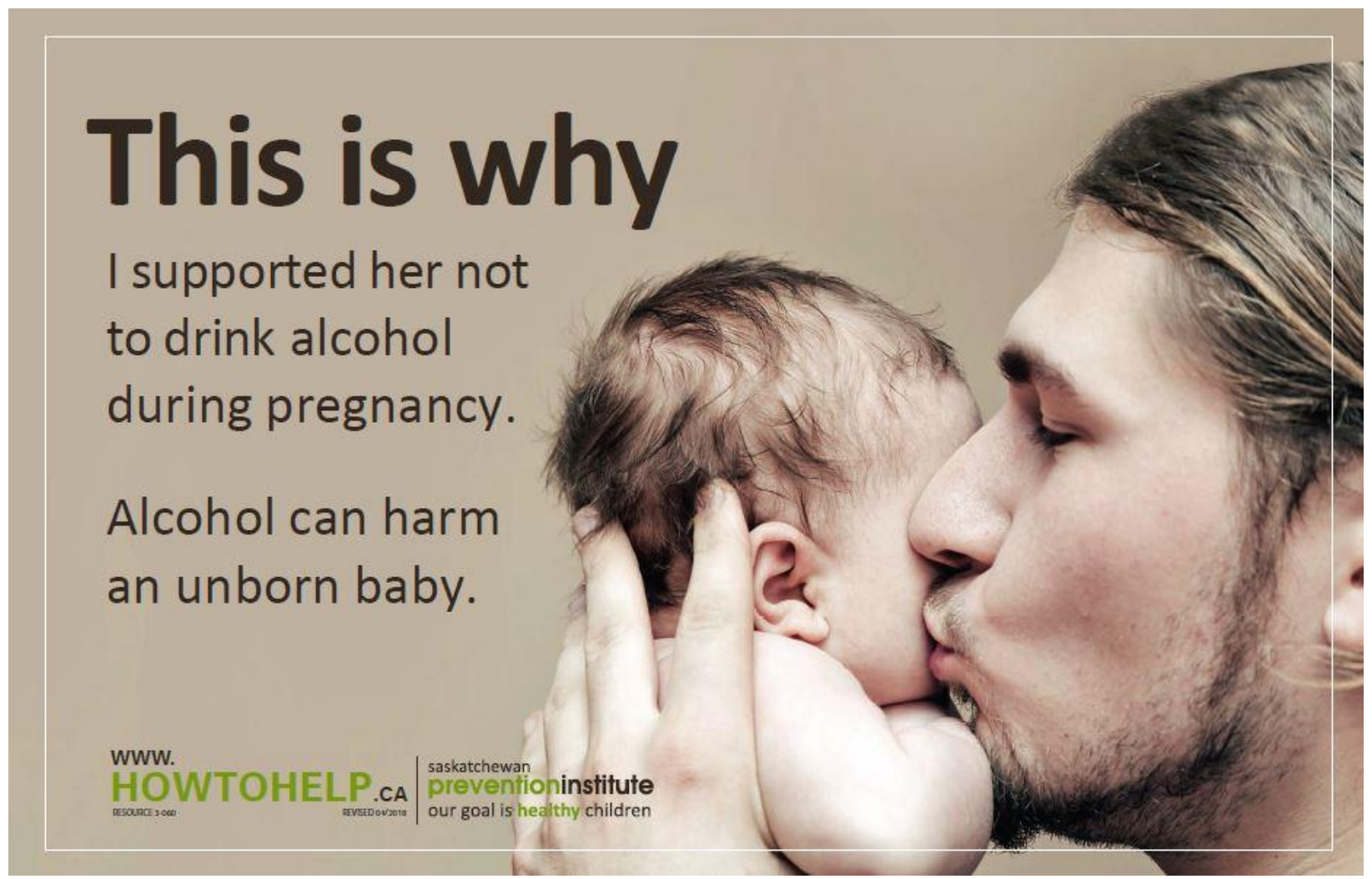

This is Why (2018)

Campaign accessed from: https://skprevention.ca/product-category/alcohol/

Image Description: The side profile of a white man's face and hand, holding up and kissing the cheek of a newborn white baby. The text is located to the right of the image and reads: "This is why I supported her not to drink alcohol during pregnancy. Alcohol can harm an unborn baby." Below the text is a website for heretohelp.ca and to the right of this text is the logo for the Saskatchewan Prevention Institute. The image is in colour, using primarily neutral tones with a dark font laid upon it. End I.D.I 


\section{Appendix: Campaign \#3}

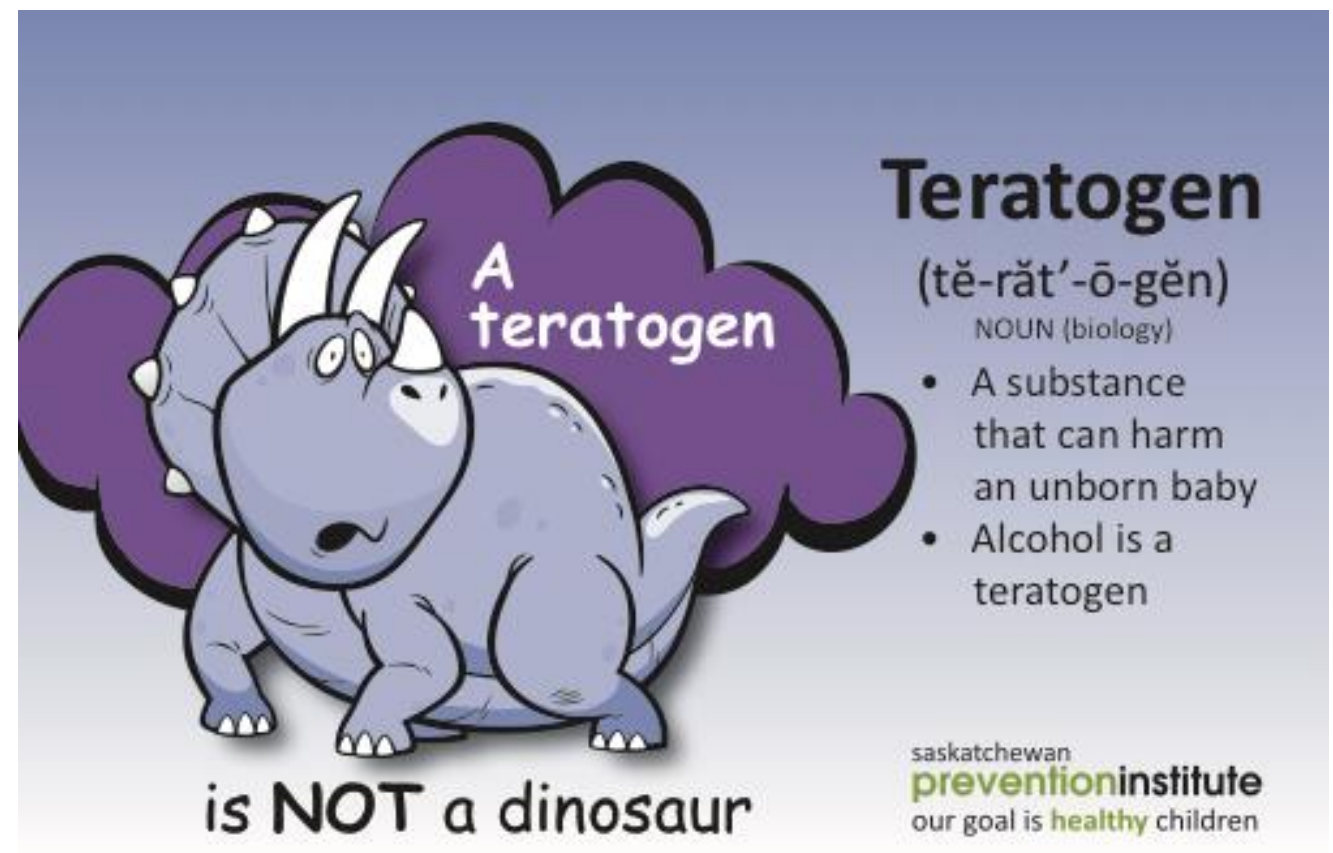

\section{A Teratogen is NOT a Dinosaur (2019)}

Campaign accessed from: https://skprevention.ca/product-category/alcohol/

Image Description: The poster depicts a cartoon image of a dinosaur, with an expression of fear on its face. Embedded beside and below the dinosaur in a child-like font is the text "A teratogen is not a dinosaur". To the right of the image is the text "Teratogen" followed by bullet points text that reads: "A substance that can harm an unborn baby" and "Alcohol is a teratogen." The colour palette is soft purples and the image looks like something out of a children's story book. End I.D.I 


\section{REFERENCES}

Ainsworth, S., \& Flanagan, S. (2019). Contradictions concerning care: Female surgeons' accounts of the repression and resurfacing of care in their profession. Gender, Work \& Organization, 27(2), 251-269.

Bagley, K., \& Badry, D. (2019). How personal perspectives shape health professionals' perceptions of fetal alcohol spectrum disorder and risk. International Journal of Environmental Research in Public Health, 16(11), 1-13.

Bagley, K. (2019). Responding to FASD: What social and community service professionals do in the absence of diagnostic services and practice standards. Advanced Dual Diagnosis, $12(1 / 2), 14-26$.

Baines, D. (2011). An overview of anti-oppressive practice: Roots, theory, tensions. In D. Baines (Ed.), Doing anti-oppressive practice: Social justice social work (2nd ed., pp. 1-24), Fernwood Publishing.

Becerra, T. A., von Ehrenstein, O. S., Heck, J. E., Olsen, J., Arah, O. A., Jeste, S. S., Rodriguez, M., \& Ritz, B. (2014). Autism spectrum disorders and race, ethnicity, and nativity: A population-based study. Pediatrics, 134(1), 63-71.

Brownstein-Evans, C. (2001). Negotiating the meaning of motherhood: Women in addiction and recovery. Journal of the Association for Research on Mothering, 3(1), 161-171.

Canadian Public Health Association. (2017). Public Health: A conceptual framework. CPHA.

Chaote, P. \& Badry, B. (2019). Stigma as a dominant discourse in Fetal Alcohol Spectrum Disorder. Advances in Dual Diagnosis, 12(1/2), 36-52. 
Chudley, A. E., Conry, J., Cook, J. L., Loock, C., Rosales, T., \& Leblanc, N. (2005). Fetal Alcohol Spectrum Disorder: Canadian guidelines for diagnosis. Canadian Medical Association Journal, 75(5), 1-25.

Cook, J. L., Green, C. R., Lilley, C. M., Anderson, S. M., Baldwin, M. E., Chudley, A. E., . . . Rosales, T. (2016). Fetal Alcohol Spectrum Disorder: A guideline for diagnosis across the lifespan. Canadian Medical Association Journal, 188(3), 191-197.

Corrigan, P. W., Shah, B. B., Lara, J. L., Mitchell, K. T., Simmes, D., \& Jones, K. L. (2018). Addressing the public health concerns of Fetal Alcohol Spectrum Disorder: Impact of stigma and health literacy. Drug and Alcohol Dependence, 185, 266-270.

Deibert, D., Short, A., \& Vescera, Z. (2019). Man who found the infant's body joins police in calling for mother to come forward. Saskatoon StarPhoenix. Retrieved from: https://thestarphoenix.com/news/local-news/police-presence-in-400-block-of-fifthavenue-north

Finnbogadottir, H. \& Dykes, A. K. (2016). Increasing prevalence and incidence of domestic violence during the pregnancy and one and a half year postpartum, as well as risk factors: a longitudinal study in Southern Sweden. BMC Pregnancy and Childbirth, 16(327), 1-12.

Fook, J. (2003). Critical deconstruction and reconstruction. In J. Fook, Social Work: Critical Theory and Practice (pp. 89-102). Sage.

General, U. S. (2005). Fetal Alcohol Spectrum Disorders. Retrieved from Center for Disease Control and Prevention: https://www.cdc.gov/ncbddd/fasd/documents/surgeongenbookmark.pdf

Goffman, E. (2006). Selections from stigma. In L.J. Davis (Ed.), The disability studies reader (2nd ed., pp. 131-40). Routledge. 
Goffman, E. (1979). Gender advertisements. Harper \& Row.

Gonzales, K. L., Jacob, M. M., Mercier, A., Heater, H., Goes Behind, L. N., Joseph, J., \& Kuerschner, S. (2018). An Indigenous Framework of the cycle of FASD risk and prevention across the generations: historical trauma, harm and healing. Ethnicity and Health,1-19.

Gringeri, E., Wahab, S. Anderson-Nathe, B. (2010). What makes it feminist?: Mapping the landscape of feminist social work research. Journal of Women and Social Work. 24(4), $390-405$.

Hanisch, C. (1970) The personal is political. In S. Firestone \& A. Koedt (Eds.), Notes from the Second Year: Women's Liberation (pp. 76-78). Major Writings of the Radical Feminists.

Health Canada. (2006). Diseases: Fetal Alcohol Spectrum Disorder. Retrieved from Government of Canada: https://www.canada.ca/en/health-canada/services/healthy-living/yourhealth/diseases/fetal-alcohol-spectrum-disorder.html

Hesse-Biber, S. N. (2012). Handbook of feminist research: Theory and practice (2nd ed.). Sage Publications, Inc.

Jackson, D., \& Mannix, J. (2004). Giving voice to the burden of blame: A feminist study of mothers' experiences of mother blaming. International Journal of Nursing Practice, 10(4), 150-8.

Jones, K. L., \& Smith, D. W. (1973). Recognition of Fetal Alcohol Syndrome in early infancy. The Lancet, 302(7836), 999-1001.

Jones, K. L., \& Streissguth, A. P. (2010). Fetal Alcohol Syndrome and Fetal Alcohol Spectrum disorders: A brief history. Journal of Psychiatry \& Law, 38, 373-382. 
Klein B. J. (2016). Functional impairment, not FASD. Canadian Medical Association Journal, 188(14), 1035-1036.

Kress, G. \& van Leeuwen, T. (2006). Reading images: The grammar of visual design (2nd ed.), Sage.

Lazar, M. (2007). Feminist critical discourse analysis: Articulating a feminist discourse praxis. Critical Discourse Studies, 4(2), 141-164.

Lupton, D. (1992). Discourse analysis: A new methodology for understanding the ideologies of health and illness. Australian Journal of Public Health, 16(2), 145-150.

Lupton, D. (2013). The social worlds of the unborn. Palgrave Macmillan.

McLennon, J. D., \& Braunberger, P. (2017). A critique of the new Canadian Fetal Alcohol Spectrum Disorder Guideline. Journal of the Canadian Academy of Child and Adolescent Psychiatry, 26(3), 179-183.

Meyer, M. (2001). Between theory, method, and politics: Positioning of the approaches to CDA. In R. Wodak \& M. Meyer (Eds.), Methods of critical discourse analysis (pp. 14-32). Sage Publications.

Miehls, D., \& Moffat, K. (2000). Constructing social work identity based on the reflexive self. British Journal of Social Work, 30, 339-348.

Mowat, D. L., \& Butler-Jones, D. (2007). Public health in Canada: A difficult history. Healthcare Papers, 7 (3), 31-36.

Pearson, H. (2020). Mother charged in 2017 case of baby found dead in Calgary dumpster on Christmas Eve. Global News. Retrieved from: https://globalnews.ca/news/6453992/christmas-eve-baby-found-calgary-charges/ 
Salmon, A. (2011). Aboriginal mothering, FASD prevention and the contestations of neoliberal citizenship. Critical Public Health, 21(2), 165-178.

Scott, I. S. (2019). Indigenous carceral motherhood: An examination of colonial, patriarchal, and neoliberal control. Aboriginal Policy Studies, 8(1), 78-103.

Sharma, M. (2019). Applying feminist theory to medical education. The Lancet. 393, 570-78.

Seymour, K. (2015). Politics and positionality: Engaging with maps of meaning. Social Work Education, 34(3), 275-285.

Tretheway, R., Taylor, J., O’Hara, L., Percival, N. (2015). A missing ethical competency? A review of critical reflection in health promotion. Health Promotion Journal of Australia. 26, 216-221.

Truth and Reconciliation Commission of Canada. (2015). Truth and Reconciliation Commission of Canada: Calls to action. Truth and Reconciliation Commission of Canada.

Van Leeuwen, T. (2008). Discourse and practice: New tools for critical discourse analysis. Oxford University Press.

Wakoma, T. T., Jampala, M., Bexhell, H., Guthrie, K., Lindow, S. (2014). A comparative study on the prevalence of domestic violence in women requesting a termination of pregnancy and those attending the antenatal clinic. British Journal of Obstetrics \& Gynaecology, $121,627-633$

Wolfson, L., Poole, N., Ninomiya M. M., Rutman, D., Letendre, S., Winterhoff, T.,... Rowan, T. (2019). Collaborative action on Fetal Alcohol Spectrum Disorder prevention: Principles for enacting the Truth and Reconciliation Commission call to action \#33. International Journal of Environmental Research and Public Health, 16(1589), 1-13. 
World Health Organization. (2012). What are the social determinants of health? Retrieved from http://www.who.int/social_determinants/

Zizzo, N., \& Racine, E. (2017). Ethical challenges in FASD prevention: Scientific uncertainty, stigma, and respect for women's autonomy. Canadian Journal of Public Health, 108(4), 414-417. 